\title{
Os Determinantes das Exportações Convencionais e das Cadeias Globais de Valor: uma Análise em Painel"
}

\section{The Determinants of Conventional Exports and Global Value Chains: a Panel Analysis}

\author{
Matheus Rissa Peroni Ribeiro ${ }^{a}$ \\ Flávio Vilela Vieira ${ }^{b}$
}

\begin{abstract}
Resumo: O objetivo deste trabalho é investigar empiricamente o desempenho e as diferenças entre as exportações convencionais e as exportações relacionadas às cadeias globais de valor (CGV) em resposta aos seguintes determinantes: taxa de câmbio em três conceitos (nível, volatilidade e desalinhamento), efeito renda e as consequências da crise financeira internacional. Para tanto, utilizam-se três métodos de dados em painel estático e dinâmico para um conjunto de 59 países, no período de 2000 a 2011. Os resultados das estimações confirmam: a) a elasticidade-preço das exportações relacionadas às CGV são maiores em comparação à elasticidade-preço das exportações convencionais; b) o aumento da volatilidade da taxa de câmbio possui menores ou nenhum impacto nas exportações vinculadas às CGV; e c) países com maiores participações a jusante nas CGV estão sujeitos a menores efeitos advindos de um desalinhamento cambial. Além disso, pode-se afirmar que a crise do subprime gerou efeitos negativos mais proeminentes nas exportações associadas às CGV em relação às exportações tradicionais.
\end{abstract}

Palavras-chave: Exportações. Cadeias globais de valor. Taxa de câmbio. Análise em painel.

\begin{abstract}
The main goal of this study is to investigate empirically the performance and differences of conventional exports and exports related to the Global Value Chains (GVC) in response two determinants: i) exchange rate in three concepts (level, volatility and misalignment); ii) and income effect; besides the consequences of the international financial crisis. For this purpose, three static and dynamic panel data methods were used for a set of 59 countries, from 2000 to 2011. The results of the estimates confirm: a) the price elasticity of exports related to GVC are higher than the price elasticity of conventional exports; b) the increase in exchange rate volatility has lower or no impact on exports linked to the GVC; c) countries with larger backward participations in GVC

\footnotetext{
* O autor Matheus Rissa Peroni Ribeiro agradece a Coordenação de Aperfeiçoamento de Pessoal de Nível Superior (CAPES) pelo apoio financeiro.

a Universidade Estadual Paulista (UNESP), Faculdade de Ciências e Letras (FCLAr), Programa de Pós-graduação em Economia. Araraquara, São Paulo, Brasil.

b Universidade Federal de Uberlândia (UFU), Instituto de Economia e Relações Internacionais (IERI), Programa de Pós-graduação em Economia. Uberlândia, Minas Gerais, Brasil.
} 
are subject to lesser effects of a currency misalignment. Subprime crisis generated more prominent negative effects on the exports associated with the GVC than traditional exports.

Keywords: Exports. Global value chains. Exchange rate. Panel analysis.

JEL Classification: C33; F10; F31.

\section{Introdução}

As cadeias globais de valor (CGV) são um fenômeno no comércio internacional intensificado pelo processo de globalização, compreendido pela integração produtiva entre os países, o qual contribuiu para a criação de novas dinâmicas e padrões para os fluxos comerciais. Nas CGV, vários países em diferentes partes do mundo desenvolvem um ou mais estágios do processo de produção de um produto, que, posteriormente, é comercializado internacionalmente. Isso contrasta com a visão tradicional do comércio internacional, na qual os bens são fabricados na íntegra em um único país e enviados como produtos finais para os mercados de exportação.

Diante dessas novas configurações do comércio internacional, surgiu a necessidade de se avaliar e mensurar os fluxos de produtos intermediários, a partir de matrizes de insumo-produto globais, para tornar factível o desenvolvimento de variáveis e índices que quantificam a inserção dos países e setores nas CGV. Com esse contexto, surgiu uma literatura heterogênea que busca compreender quais são as principais causas e consequências de uma maior participação dos países nas CGV. Já a literatura acerca da relação entre a taxa de câmbio e o comércio internacional se intensificou com o aumento da volatilidade cambial após o fim do padrão ouro. Mais recentemente, após a crise do subprime, o debate sobre os possíveis impactos de um desalinhamento cambial em torno de uma taxa de câmbio de equilíbrio sobre os fluxos comerciais se intensificou.

Adjacente a essas duas literaturas distintas, uma nova linha de pesquisa ganhou espaço, convergindo pesquisas que analisam os impactos da taxa de câmbio sobre o comércio com a literatura que avalia as implicações de uma maior inserção nas CGV, desenvolvendo estudos empíricos para avaliar como o fenômeno das CGV alterou as elasticidades-preço das exportações e o impacto da volatilidade cambial nos fluxos comerciais. Desse modo, com o intuito de contribuir para essa literatura, o objetivo deste trabalho consiste em realizar uma investigação econométrica a fim de observar as diferenças entre as exportações convencionais, as quais envolvem apenas dois países na compra e venda de produtos finais, e as exportações a jusante às CGV, bens ou serviços intermediários exporta- 
dos por um país que são utilizados e/ou transformados pelo parceiro comercial para a produção de suas próprias exportações para outros países, em resposta ao comportamento da taxa de câmbio real efetiva (TCREF) em três conceitos: nível, volatilidade e desalinhamento. Além disso, é observada a elasticidade-renda das exportações e o impacto da crise do subprime nas duas variáveis dependentes citadas. Para tanto, é utilizado o método de dados em painel estático (efeitos fixos) e dinâmico (system e difference GMM) para um conjunto de 59 países desenvolvidos e em desenvolvimento, no período compreendido entre 2000 e 2011.

De acordo com a literatura empírica analisada, a primeira hipótese indica que exportações a jusante às CGV possuem maior sensibilidade diante de mudanças da taxa de câmbio, apresentando uma elasticidade-preço das exportações maior em comparação à elasticidade-preço das exportações convencionais. A segunda hipótese sugere que exportações relacionadas às CGV possuem pouco ou nenhum impacto diante de aumentos da volatilidade cambial e, em contrapartida, as exportações tradicionais possuem impactos negativos e significantes. Ademais, não foram encontrados trabalhos que analisam as diferenças das participações nas CGV sobre os possíveis impactos do desalinhamento cambial nos fluxos comerciais. Por fim, não há consenso sobre como as CGV alteraram as relações entre renda externa e exportações, impossibilitando a apresentação de uma hipótese em relação à elasticidade-renda das exportações.

Em um contexto de intensificação da produção em CGV, torna-se pertinente entender qual a influência desse fenômeno sobre a relação entre a taxa de câmbio e as exportações, além de identificar as mudanças da elasticidade-renda das exportações e os impactos da crise financeira no âmbito das CGV. Embora já existam alguns estudos empíricos que respondam uma parcela desse conjunto de questões, este estudo contribui para a literatura ao abordar de forma unificada a influência da taxa de câmbio em seus três conceitos, da renda estrangeira e da crise do subprime sobre as exportações convencionais e as exportações vinculadas às CGV.

Portanto, além dessa introdução, o trabalho está estruturado em mais quatro seções. Na segunda seção, realiza-se uma breve revisão da literatura teórica e empírica dos fenômenos das CGV e uma análise da literatura empírica que trabalha a relação entre a taxa de câmbio e o comércio internacional no contexto das CGV. Na terceira seção, apresentam-se as principais bases de dados utilizadas, as metodologias adotadas para a mensuração da proxy de renda estrangeira, da volatilidade e do desalinhamento cambial. Na quarta seção, demonstram-se os métodos, modelos e resultados econométricos. Por fim, na quinta seção, traçam-se as considerações finais do estudo. 


\section{Revisão da Literatura}

Esta seção apresenta o arcabouço teórico e empírico deste artigo. Primeiro realiza-se uma breve discussão sobre as características, a mensuração e determinadas evidências sobre o fenômeno das CGV. Posteriormente, desenvolve-se uma revisão da literatura acerca da relação entre taxa de câmbio, volatilidade cambial, desalinhamento da taxa de câmbio e o comércio internacional no contexto CGV.

\subsection{Cadeias Globais de Valor: Fundamentação Teórica, Mensuração e Evidências Empíricas}

Os estudos a respeito das CGV foram acompanhados pela evolução de pesquisas acerca da intensificação do processo de globalização e seu desencadeamento na fragmentação da produção global em complexas redes produtivas, gerando uma maior interdependência entre os países. Gereffi et al. (1994) desenvolvem um novo conjunto de categorias conceituais para analisar novos padrões de organização e desenvolvimentos de indústrias através da participação dessas cadeias. Identificam as CGV por cadeias de fornecimentos globalmente localizadas e formadas por diversos setores, que são caracterizados por atividades como: fabricação de um bem desde seus componentes até seu estado bruto; distribuição, transporte e venda; e serviços de pesquisa e desenvolvimento (PEBD), design e montagem. Em suma, qualquer processo que adicione valor ao produto ao longo de sua cadeia de produção.

O surgimento das CGV foi acompanhado por uma expansão intensa dos fluxos do comércio internacional, uma vez que os bens intermediários passaram a cruzar cada vez mais as fronteiras durante o processo de produção. Desse modo, a origem da formação das CGV está relacionada com os avanços da tecnologia da produção, as inovações em transporte e comunicação, a ampliação da variedade e alcance dos serviços oferecidos, as reformas liberalizantes com quedas de barreiras comerciais, movimentos de padronização de componentes, entre outros elementos (GEREFFI, 1994, 1999).

Baldwin (2012) salienta que as CGV são eminentemente regionalizadas pois são condicionadas pelos custos de transporte menores entre países próximos, maior facilidade na coordenação entre as diferentes etapas e tarefas da produção a partir de menores barreiras tarifarias e barreiras técnicas, facilidades logísticas e redução nos custos das transações e dos serviços associada à proximidade regional. Johnson e Noguera (2017) acrescentam que a participação nas CGV ocorreu de forma distinta em diferentes regiões, pois a inserção nas CGV depende de vários fatores específicos que nem todos os setores e países possuem: propensão a exportar, capacitações industrias, políticas de investimento em inovação e políticas 
comerciais menos restritas. Ademais, o padrão da inserção nas CGV depende de infraestrutura adequada e de qualidade, assim como da intensidade tecnológica da economia. Além disso, o contexto institucional no qual a cadeia de valor está inserida - representado pelas circunstâncias legislativas trabalhistas e fiscais, ambiente de negócios favorável aos investimentos - são determinantes importantes na integração às CGV (OECD, 2013). ${ }^{1}$

Diante dessas novas configurações do comércio internacional, pesquisadores buscam avaliar e quantificar o comércio de produtos intermediários, bem como desenvolver índices capazes de medir o nível de fragmentação - via decomposição do valor adicionado das exportações a partir de matrizes insumo-produto internacionais e estatísticas de comércio bilateral - de produtos, setores e países.

Nesse contexto, as decomposições das exportações convencionais brutas se justificam devido à presença de viés nessas medidas, pois estas não consideram que uma parcela do conteúdo da pauta exportadora de um país é formada por produtos intermediários importados que são incluídos no processo produtivo. Isto é, se um determinado país exporta um bem que possui componentes importados, ao atravessar a fronteira tais componentes terão uma dupla contagem nas exportações totais do país (KOOPMAN; WANG; WEI, 2012).

Koopman et al. (2010) constroem o índice VS, uma medida de decomposição das exportações brutas que representa a relação dos insumos importados utilizados nas exportações brutas. Quando um país possui elevada participação VS, significa que possui uma forte dependência de bens e serviços intermediários externos para sua produção doméstica. Os autores também desenvolveram o cálculo do índice VS1, que expressa o conteúdo doméstico adicionado exportado por um país que, depois de transformado, é reexportado para países terceiros. A economia que possui o índice VS1 alto é caracterizada como forte fornecedora de produtos e serviços intermediários incorporados nas exportações de países terceiros, tornando-se mais dependente das CGV. Ademais, os autores criaram um indicador incluindo simultaneamente os índices VS e VS1, chamado de GVC participation, que captura a inserção nas cadeias de forma integrada.

A participação nas CGV é formada pelo índice VS, aqui também apresentado como valor adicionado estrangeiro (VAE_CGV), conhecido por ligação a montante (ou participação para trás) nas CGV, está relacionado ao conteúdo importado das exportações em valor adicionado, e o índice VS1, representado pelo valor adicionado doméstico, que é exportado e usado pelo parceiro comercial para a

1 Outros fatores, mais ligados à organização industrial, são destacados como condicionantes para a magnitude da integração nas CGV: a) a estrutura de governança configura como serão distribuídas as atividades (PED, produção, marketing, montagem e distribuição) ao longo das cadeias; b) o upgrading, nesse contexto, é a possibilidade de mudança de um padrão de especialização de menor valor adicionado (VA) para atividades de maior VA, implicando em maior qualificação tecnológica e melhoria no desempenho do VA nas exportações. Para mais informações, ver Humphrey e Schmitz (2002) e Sturgeon (2005). 
produção de suas próprias exportações para outros países, designado também por ligações a jusante (ou participação para frente) e está vinculado às exportações relacionadas às CGV (VAD_CGV) (OECD, 2013).

Com base nesses indicadores, trabalhos recentes utilizam métodos econométricos para medir a importância dos índices relacionados ao comércio das CGV na função de variável explicativa e também o impacto de outras variáveis na determinação da participação dos países nas redes globais de produção, como variável explicada.

Estevadeordal, Blyde e Suominen (2013) realizam uma investigação acerca da influência da distância para a participação dos países nas CGV, e os resultados indicam que o aumento de $10 \%$ da distância entre dois países reduz, em média, cerca de $65 \%$ das participações para trás nas CGV. Banga (2016) examina o impacto da participação nas CGV sobre o crescimento do emprego na Índia e revelam que o índice VS influencia negativamente o crescimento do emprego, e o índice VS1 não apresenta impacto estatisticamente significativo no emprego.

Hermida (2016), em um dos objetivos de sua tese, observa o papel da fragmentação e da participação dos países nas CGV sobre o crescimento econômico e apresenta evidências que ambos os índices, VS e GVC participation, possuem efeitos significativos e positivos. Dollar, Ge e Yu (2017) examinam a ligação entre a qualidade das instituições e a participação nas CGV e apontam uma relação positiva e significativa entre as duas variáveis. O artigo de Rubínová (2017) investiga o impacto dos acordos comerciais sobre os fluxos comerciais de manufaturados, e os resultados mostram que os acordos de livre-comércio reforçam a participação nas CGV das economias.

\subsection{Taxa de Câmbio e Comércio Internacional: Evidências Empíricas no Contexto das Cadeias Globais de Valor}

A literatura que aborda a questão dos impactos das alterações da taxa de câmbio sobre o comércio internacional surgiu diante do aumento do risco gerado pelas oscilações das taxas de câmbio. Auboin e Ruta (2011), nesse contexto, elaboram uma revisão de 43 trabalhos empíricos realizados entre 1984 e 2005, os quais possuem diferentes especificações, técnicas de estimação e amostragem. Em conclusão, demonstram que variações da taxa de câmbio frequentemente geram efeitos adversos nas exportações, e, mesmo que não haja consenso na literatura, a maioria dos trabalhos indica que a volatilidade cambial possui uma relação negativa com os fluxos comerciais.

No entanto, considerando que a relação entre as taxas de câmbio e o comércio varia ao longo do tempo à medida que as mudanças na integração mundial se materializam, trabalhos empíricos recentes propuseram entender de que maneira 
o surgimento desse fenômeno pode ter modificado a forma como o comércio responde às mudanças dos preços relativos internacionais.

Ahmed, Appendino e Ruta (2015) desenvolvem uma análise em painel para 46 países, de 1996 a 2012, e encontram evidências de que a elasticidade do câmbio real efetivo das exportações (volume) de manufaturados tem caído ao longo dos últimos anos e associa essa queda ao desenvolvimento das CGV. A ideia é de que à medida que os países se tornem mais integrados ao processo produtivo internacional, uma depreciação cambial tem o poder de melhorar a competitividade apenas em uma fração das exportações finais de bens.

Com base em um modelo de dados em painel com efeitos fixos envolvendo 57 países, entre 1995 e 2011, Cheng et al. (2016) examinam separadamente o impacto das mudanças da TCREF nas exportações e importações relacionadas às CGV - Valor adicionado doméstico (VAD) e Valor adicionado estrangeiro (VAE) - e comparam a resposta com elasticidade-preço das exportações e das importações brutas tradicionais. Os resultados indicam que, nos fluxos comerciais no âmbito das CGV, uma apreciação real não apenas reduz as exportações de VAD (um resultado convencional), mas também diminui as importações de VAE (ao contrário da teoria do comércio tradicional). Esse resultado é consistente com a noção de que o VAD e VAE relacionados às CGV são complementares na produção, portanto exportar menos também reduz a demanda derivada de importados VAE.

O artigo de Kang e Dagli (2018) utiliza um painel por meio de um modelo gravitacional com dados de exportações bilaterais de 45 países. O trabalho apresenta uma diminuição do impacto da taxa de câmbio sobre as exportações de $0,10 \%$ diante de um aumento de $1 \%$ da participação do VAE_CGV sobre as exportações totais. De Soyres et al. (2018), a partir do método de dados em painel com efeitos fixos com 40 países, entre 1995 e 2011 , procuram compreender quais são os impactos das ligações a montante e a jusante nas CGV sobre a elasticidade-preço das exportações. Os autores constatam que economias com maiores participações a montante (VAE_CGV) sobre o total das exportações reduzem o repasse das variações cambiais para os preços e diminuem a elasticidade-preço das exportações, ao mesmo tempo que quotas maiores a jusante (VAD_CGV) no total exportado torna as exportações mais sensíveis a mudanças da taxa de câmbio.

Além da análise dos impactos das CGV sobre as elasticidades comerciais, Sato e Zhang (2018) avançam na literatura e investigam como as CGV afetam o efeito da volatilidade da taxa de câmbio sobre o comércio. Para isso, utilizam o modelo de painel dinâmico com dados cobrindo 29 países e 18 setores industriais no período de 1997 a 2012. Os autores indicam que a participação das CGV reduz o impacto negativo da volatilidade da taxa de câmbio nas exportações de manufaturados em $74 \%$, em média. 
Este trabalho propõe investigar também os efeitos da participação para frente nas CGV sobre o impacto do desalinhamento cambial nas exportações. A análise no contexto das CGV torna-se interessante, pois a produção fragmentada em vários países pode compensar o efeito do desalinhamento cambial. Ou seja, um país que apresenta o câmbio desvalorizado em torno da sua taxa de câmbio de equilíbrio sujeita-se a ter sua competitividade no preço das exportações anulada ao importar insumos com preços mais elevados. Cabe salientar que não foram encontrados trabalhos que abordassem o impacto do desalinhamento da taxa de câmbio no contexto das CGV, mas, apesar disso, existem na literatura trabalhos que analisam os impactos potenciais do desalinhamento sobre as exportações convencionais.

A literatura sobre câmbio de equilíbrio e desalinhamento é relativamente extensa, e os diversos conceitos podem ser sumarizados por cinco abordagens: a) a abordagem da paridade do poder de compra (PPC); b) a taxa de câmbio de equilíbrio fundamental (Feer) de Williamson (1983, 1994); c) a taxa de câmbio real natural (Natrex) de Stein (1994, 1995, 2002); d) o equilíbrio macroeconômico (IMF) de Isard e Faruqee (1998) e Faruqee, Isard e Masson (1999); e e) a abordagem comportamental da taxa real de câmbio (Beer) de Clark e MacDonald (1999).

A abordagem desenvolvida por Bresser-Pereira (2011) e Bresser-Pereira, Oreiro e Marconi (2017) considera que a taxa de câmbio consiste em um preço macroeconômico que flutua em torno do seu equilíbrio corrente. No caso das economias em desenvolvimento, com o Brasil incluso, a taxa de câmbio não flutua em torno de um equilíbrio corrente por haver uma tendência à sobreapreciação crônica. Dadas essas características, ao final o resultado é uma alteração na estrutura produtiva desses países, que acabam por financiar seus déficits em conta-corrente via aumento das exportações de recursos naturais. Associado a esse fenômeno, encontra-se uma tendência à desindustrialização e, desse modo, o mais correto seria ter-se uma noção de taxa de câmbio de equilíbrio industrial para neutralizar esse efeito, que é, dentre outras coisas, desfavorável ao crescimento econômico de longo prazo e ao aumento da produtividade.

Nesse contexto, Haddad e Pancaro (2010) estimam um painel com efeitos fixos para 187 países no interregno de 1950 a 2004, e, especificamente nas economias em desenvolvimento, um aumento de 50\% na desvalorização em torno de uma taxa de câmbio de equilíbrio está associado a um aumento anual de 1,8\% na exportação sobre o PIB. Nicita (2013)especially with regard to antidumping interventions. ?? 2013 CEPII (Centre d'Etudes Prospectives et d'Informations Internationales estima modelos de efeitos fixos em dados em painel composto por 100 países no período de 2000 a 2009, e os resultados indicam que a subvalorização sustentada do câmbio promove as exportações e restringe as importações, a inversa é verdadeira (sobrevalorização). 
Por fim, uma questão que vem sendo discutida mais recentemente é como medir a TCREF, ou seja, em última instância, como avaliar a competitividade, conforme mostra Bayoumi, Salgado e Mills (2013). A maneira convencional de medir a TCREF é baseada na ideia de que os bens comercializados são bens finais, mas tal abordagem é claramente limitada, pois mais de dois terços do comércio envolve bens intermediários. Os autores sugerem a necessidade de se mensurar dois tipos de TCREF. Um deles deve levar em conta as etapas produtivas ao invés de bens, utilizando uma ponderação a partir do valor adicionado do comércio bilateral. Uma segunda mensuração da TCREF envolve o cálculo dos pesos a partir dos conteúdos domésticos e estrangeiros na composição do valor adicionado. Ademais, destacam que alterar os pesos do comércio é importante, mas as escolhas dos índices de preços também são importantes.

\section{Procedimentos Metodológicos}

Nesta seção são apresentadas as base de dados utilizadas e a metodologia para a mensuração da volatilidade e do desalinhemento cambial, além do procedimento para o cálculo da proxy de renda externa, que compreendem as variáveis utilizadas nos modelos econométricos.

\subsection{Base de Dados}

A base de dados de matrizes insumo-produto internacionais utilizada é a Trade in value added (TiVA) da OECD.STAT (2016). A sua escolha se justifica pela quantidade de países na sua amostra e por obter dados anuais ininterruptos das duas variáveis dependentes aqui trabalhadas, características essenciais para o método econométrico proposto. A base de dados compreende 63 países, discriminadas em 34 atividades produtivas, no período de 1995 a $2011 .^{2}$

Porém, os dados utilizados nas regressões compreendem apenas 59 países, devido à indisponibilidade de outros dados necessários para a construção dos modelos, além de cobrir apenas o período de 2000 a 2011 por quatro motivos: a) as novas configurações do comércio internacional no contexto das CGV ocorreram de forma mais relevante a partir da década de 2000 (HERMIDA, 2016); b) o final da década de 1990 foi marcado por crises de vulnerabilidade externa e crises cambiais; c) ocorreram, em torno do ano 2000, duas mudanças na conjuntura macroeconômica com possíveis efeitos para a inserção externa dos países da amostra (consolidação da União Europeia, por meio da adoção de uma moeda comum,

2 Em função das duas variáveis serem organizados em preços correntes, foram deflacionadas as séries usando o índice de preços ao consumidor do World Development Indicators (WDI). 
em 1999, e a entrada da China na Organização Mundial do Comércio (OMC) em 2001; e d) as estimações dos modelos de painel dinâmico são mais apropriados para uma dimensão cross-section elevada a uma dimensão temporal pequena, dificultando o uso da amostra total disponível.

A TCREF, variável explicativa e também utilizada para a mensuração da volatilidade e do desalinhamento cambial, foi escolhida para captar melhor a competitividade de preços das exportações, dado que esta é caracterizada por um índice composto pelas médias ponderadas das taxas de câmbio bilaterais de cada país, ajustadas pelo índice de preços ao consumidor relativos aos seus principais parceiros comercias. A fonte da TCREF é o Bank for International Settlements, e um aumento do índice indica uma apreciação da moeda frente a uma ampla cesta de moedas. Como resultado, espera-se um coeficiente negativo em relação às exportações e, também, considera-se a hipótese de que a elasticidade-preço das exportações seja maior em relação às exportações relacionadas às CGV se comparada às exportações convencionais.

\subsection{Mensuração da Proxy de Renda Estrangeira}

A primeira etapa para o calculo da proxy de renda extrangeira (PIB_Externo) é dada pela ponderação dos pesos específicos das exportações de cada parceiro comercial j sobre o total exportado para cada ano $t$ do país $i$. Para o ano $t$, a participação do país j nas exportações do país i é dada por:

$$
\operatorname{ExportPond}_{t, i, j}=X_{t, i, j} / \sum X_{t, i, j}
$$

em que é a exportação do país i para o país j no ano t, com j mudando ao longo do tempo.

A segunda etapa compreende a multiplicação do PIB deflacionado ${ }^{3}$ de cada parceiro comercial j com seu respectivo peso (ExportPond) nas exportações totais do país i no ano t. Dessa forma, o PIB externo ponderado pelo comércio para o país i no ano t é dado por:

$$
P_{\text {PIB_Externo }}, i, j=\sum \text { ExportPond }_{t, i, j} \times \text { PIB }_{t, j}
$$

Essa proxy de renda extrangeira, proposta pelos autores Cronovich e Gazel (1998), foi calculada com base na participação dos 10 maiores parceiros comercias. Espera-se um sinal positivo para o PIB_Externo, pois sua elevação geralmente causa um aumento das exportações.

3 Os dados do deflator implícito do PIB foram coletados do WDI. 


\subsection{Mensuração da Volatilidade e do Desalinhamento Cambial}

A medida de volatilidade, sugerida por Vieira e McDonald (2016), é calculada usando a primeira diferença do log da taxa de câmbio real efetiva (DLTCREF), com base na modelagem de cada série de tempo usando um processo $\mathrm{ARCH}$ -GARCH. Para se escolher o melhor modelo ajustado, foi utilizado os critérios de informação de Akaike (1978) e Schwarz (1978), usando até quatro defasagens. ${ }^{4}$ Espera-se, para a volatilidade, um coeficiente estimado negativo, pois a maioria dos trabalhos da literatura indicam que maiores volatilidades da TCREF geram impactos negativos nas exportações. Além disso, há a hipótese de que a volatilidade cambial possua efeitos menos negativos em relação às exportações associadas às CGV em comparação às exportações tradicionais.

A medida utilizada para calcular o desalinhamento da taxa de câmbio foi o efeito Balassa-Samuelson (BS), corrigindo o efeito PPC dos países. Para capturar o efeito BS, utiliza-se o log do PIB real per capita (PIBt):

$$
\ln \mathrm{TCREF}_{t}=\alpha+\beta \ln \mathrm{PIB}_{t}+\mathrm{u}_{t}
$$

no qual o resíduo u estimado é a proxy do desalinhamento cambial (DESAL) corrigido pelo efeito BS.

Para fins de robustez, foi calculada uma medida ampliada de desalinhamento (DESAL_Amp), proposta por Vieira e McDonald (2012)which means that a more depreciated (appreciated, a qual inclui as seguintes variáveis, além do efeito BS: ativos estrangeiros líquidos (NFA) como porcentagem do PIB usada na função de proxy para capturar o ajuste externo - os países com melhor posição na conta-corrente experimentam uma valorização do câmbio real ao longo do tempo; e termo de troca do comércio (TT), que apresenta a relação entre os preços das exportações sobre as importações, e com melhor desempenho comercial ocorre a valorização da taxa de câmbio real ao longo do tempo. Por fim, o consumo governamental em relação ao PIB (GOV) busca capturar mudanças na composição da demanda, uma vez que, geralmente, os gastos do governo são mais intensos em bens não comercializáveis e dado que tais bens são mais inelásticos, o resultado é uma valorização da taxa de câmbio real. ${ }^{5}$

O sinal esperado, tanto para o DESAL, quanto para o DESAL_Amp em relação às exportações, é um coeficiente estimado negativo, porque uma elevação de seus valores indica uma sobrevalorização da taxa de câmbio.

4 O Quadro 1, presente no Apêndice A, reporta os modelos ARCH-GARCH selecionados para cada um dos 59 países.

5 As fontes das variáveis para o cálculo dos desalinhamentos são: PIB (efeito BS) - Pen World Table 9.0; NFA - External Wealth of Nations Mark II; TT - WDI; GOV - WDI. 


\section{Métodos, Modelos e Resultados Econométricos}

Para se estimar como a taxa de câmbio real efetiva, a volatilidade cambial e as duas versões de desalinhamento cambial influenciam as exportações brutas e o valor adicionado doméstico relacionado às CGV, optou-se por utilizar a metodologia de dados em painel estático e dinâmico. Essa opção é atrelada ao fato dos principais trabalhos, mencionados na revisão da literatura, utilizarem um dos dois métodos.

Com relação ao método de painel estático, a estimação por efeitos fixos (EF) busca controlar os efeitos das variáveis omitidas que se alteram entre indivíduos, conservando as variações ao longo do tempo a partir de uma transformação para remover o efeito não observado 0 . Dessa forma, considera-se que o intercepto muda de um indivíduo para o outro, permanecendo constante na dimensão temporal, enquanto os parâmetros estimados são constantes para os indivíduos ao longo do tempo (WOOLDRIDGE, 2001).

O método de dados em painel dinâmico, formulado pelos trabalhos de Arellano e Bond (1991), Arellano e Bover (1995) e Blundell e Bond (1998) - que desenvolveram o system GMM e o difference GMM - é caracterizado pela presença da variável dependente defasada entre os regressores e por tratar todas as variáveis explicativas como endógenas. Além disso, as estimações pelo GMM lidam com a provável existência de endogeneidade das variáveis explicativas presente nos modelos, evitando um possível viés nas estimações. Para isso, relaxam a hipótese de exogeneidade estrita, diferentemente do método por efeitos fixos (EF). A distinção dos dois métodos se encontra na utilização dos instrumentos, enquanto o system GMM utiliza como instrumentos as primeiras diferenças das variáveis especificadas em nível e as variáveis defasadas em primeira diferença, no método difference GMM a equação em nível é excluída e consideram-se apenas as variáveis em primeira diferença (ROODMAN, 2009a)

Para verificar a validade da exogeneidade dos instrumentos, o primeiro teste é a estatística $J$ de Hansen para restrições de sobreidentificação, na qual a hipótese nula conjunta é que os instrumentos são válidos, ou seja, não são correlacionados com o termo de erro e os instrumentos são corretamente excluídos da equação estimada. O segundo, teste de diferença de Hansen (Hansen Diff), tem como hipótese nula que os instrumentos em nível são válidos e não correlacionados com o termo de erro da equação de diferença, devendo, portanto, ser aceita. Além desses, os testes Arellano-Bond AR (1) e AR (2) são importantes para revelar se existe correlação das variáveis explicativas com os resíduos, sendo Ho a ausência de correlação serial, podendo ocorrer autocorrelação de primeira ordem ( $p$-valor $<0,05$ para AR (1)), mas devendo apresentar ausência de autocorrelação de segunda ordem ( $p$-valor > 0,05 para AR (2))(ROODMAN, 2009a)dynamic panel estimators. The techniques and their implementation in Stata, a statistical software 
package widely used in the research community, are an important input to the careful applied research CGD advocates. The techniques discussed are specifically designed to extract causal lessons from data on a large number of individuals (whether countries, firms or people.

Além disso, Roodman (2009b)the estimators easily gen- erate instruments that are numerous and, in systemGMM,potentially suspect.Alarge instrument collection overfits endogenous variables even as it weakens the Hansen test of the instruments' joint validity. This paper reviews the evidence on the effects of instrument proliferation, and describes and simulates simple ways to control it. It illustrates the dangers by replicating Forbes [American Economic Review (2000 salienta sobre um problema relacionado à proliferação de instrumentos e demonstra que, à medida que a dimensão temporal aumenta, o número de instrumentos pode se tornar maior em comparação ao tamanho da amostra, o que pode sobreajustar as variáveis endógenas e falhar ao corrigir seus componentes endógenos. Nesse sentido, o autor sugere aplicar os comandos collapse ou laglimits para reduzir o número de instrumentos.

O objetivo central da investigação econométrica dos modelos de exportações convencionais (EXPORT) e exportações relacionadas às CGV (VAD_CGV) é avaliar a significância estatística e os coeficientes das variáveis de interesse: a) elasticidade-preço das exportações (TCREF); b) volatilidade cambial (VOLAT); c) desalinhamento cambial (DESAL); e d) desalinhamento cambial ampliado (DESAL_Amp), utilizando-se os modelos de painel estático (EF) e painel dinâmico (system e difference GMM). Além disso, observar a elasticidade-renda das exportações, representada pela proxy de renda estrangeira (PIB_Externo) e os efeitos da crise financeira (DUCRISE09). Dessa maneira, pretende-se observar a diferença dos impactos dessas variáveis explicativas sobre as duas variáveis dependentes.

Cabe ressaltar que a investigação econométrica concentra-se na importância da taxa de câmbio (nível, volatilidade e desalinhamento) e da renda externa para as exportações, desconsiderando outras possíveis variáveis que a literatura sobre o tema indica. Assim, não se pretende avaliar todos os possíveis determinantes das exportações. ${ }^{6}$

A representação dos quatro modelos das variáveis dependentes (X) EXPORT e VAD_CGV é dada pelas seguintes equações:

Modelo 1: $D L(X)_{i t}=\beta_{1} D L(X)_{i t-1}+\beta_{2} D L\left(P I B_{E x t e r n o}\right)_{i t}+\beta_{3} L(T C R E F)_{i t-1}+\mu_{i t}$

Modelo 2: $D L(X)_{i t}=\beta_{1} D L(X)_{i t-1}+\beta_{2} D L\left(P I B_{E x t e r n o}\right)_{i t}+\beta_{3} V O L A T_{i t}+\varepsilon_{i t}$

Modelo 3: $D L(X)_{i t}=\beta_{1} D L(X)_{i t-1}+\beta_{2} D L\left(P I B_{E x t e r n o}\right)_{i t}+\beta_{3} D E S A L_{i t-1}+\gamma_{i t}$

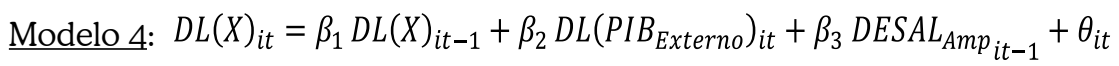

6 Ver Alfaro et al. (2019) para maiores detalhes sobre outros fatores que possam ser considerados como determinantes das exportações. 
As variáveis dependentes e o PIB_Externo são expressos em primeira diferença do log natural (DL), e a TCREF, apenas em log natural (L). Essas transformações se devem ao fato da necessidade de todas as variáveis serem estacionárias, ou seja, possuírem uma função aleatória no decorrer do tempo. O Quadro 2, presente no Apêndice A, sistematiza os testes de raiz unitária e indicam que as variáveis VOLAT, DESAL e DESAL_Amp são estacionárias em nível.

Para fins de comparação com os métodos de painel dinâmico, foram adicionados os valores defasados das variáveis dependentes às regressões do painel estático para incluir efeitos dinâmicos. Além disso, as variáveis explicativas TCREF, DESAL e DESAL_Amp foram defasadas em $t$ - 1 , isso se explica devido à existência de defasagens no impacto de uma desvalorização (ou apreciação) da taxa de câmbio sobre os fluxos comerciais. ${ }^{7}$ Por fim, optou-se por incluir em todos os modelos uma dummy (DUCRISE09) para observar os efeitos do ano subsequente ao da crise do subprime.

As estimações são apresentadas nas tabelas a seguir. Os resultados da Tabela 1 apresentam os resultados para as estimações por painel estático (efeitos fixos) e as Tabelas 2 e 3, as estimações por painel dinâmico pelos métodos system e difference GMM, respectivamente.

Tabela 1 - Resultado das estimações pelo método de dados em painel estático (efeitos fixos)

\begin{tabular}{|c|c|c|c|c|c|c|c|c|}
\hline \multirow{2}{*}{$\begin{array}{l}\begin{array}{l}\text { Variável } \\
\text { dependente (X) }\end{array} \\
\text { Modelos } \\
\end{array}$} & \multicolumn{4}{|c|}{ DLEXPORT } & \multicolumn{4}{|c|}{ DLVAD_CGV } \\
\hline & 1 & 2 & 3 & 4 & 1 & 2 & 3 & 4 \\
\hline \multirow[t]{2}{*}{ Dependente $(-1)$} & $-0,112^{* *}$ & $-0,101^{* *}$ & $-0,088^{* *}$ & $-0,088^{* *}$ & $-0,150 * * *$ & $-0,152^{* * *}$ & $-0,140 * * *$ & $-0,148^{* * * *}$ \\
\hline & $(0,044)$ & $(0,039)$ & $(0,044)$ & $(0,042)$ & $(0,037)$ & $(0,032)$ & $(0,037)$ & $(0,037)$ \\
\hline \multirow[t]{2}{*}{ DLPIB_Externo } & $0,158 * * *$ & $0,164^{* * *}$ & $0,158^{* *}$ & $0,150 * *$ & 0,061 & 0,064 & 0,062 & 0,055 \\
\hline & $(0,058)$ & $(0,060)$ & $(0,061)$ & $(0,059)$ & $(0,061)$ & $(0,068)$ & $(0,068)$ & $(0,067)$ \\
\hline \multirow[t]{2}{*}{ LTCREF $(-1)$} & $-0,184^{* * *}$ & & & & $-0,140 * * *$ & & & \\
\hline & $(0,032)$ & & & & $(0,038)$ & & & \\
\hline \multirow[t]{2}{*}{ VOLAT } & & $-0,257^{* * *}$ & & & & $-0,159 * * *$ & & \\
\hline & & $(0,004)$ & & & & $(0,007)$ & & \\
\hline \multirow[t]{2}{*}{$\operatorname{DESAL}(-1)$} & & & $-0,209 * * *$ & & & & $-0,148^{* * *}$ & \\
\hline & & & $(0,030)$ & & & & $(0,052)$ & \\
\hline \multirow[t]{2}{*}{ DESAL_Amp (-1) } & & & & $-0,296 * * *$ & & & & $-0,128^{*}$ \\
\hline & & & & $(0,053)$ & & & & $(0,072)$ \\
\hline \multirow[t]{2}{*}{ DUCRISE09 } & $-0,311^{* * *}$ & $-0,309 * * *$ & $-0,309 * * *$ & $-0,308^{* * *}$ & $-0,437^{* * *}$ & $-0,436 * * *$ & $-0,435^{* * *}$ & $-0,436 * * *$ \\
\hline & $(0,017)$ & $(0,017)$ & $(0,017)$ & $(0,018)$ & $(0,022)$ & $(0,023)$ & $(0,023)$ & $(0,023)$ \\
\hline $\begin{array}{l}\text { Número de } \\
\text { observações }\end{array}$ & 649 & 649 & 649 & 648 & 649 & 649 & 649 & 648 \\
\hline $\mathrm{R}^{2}$ & 0,718 & 0,714 & 0,712 & 0,706 & 0,728 & 0,725 & 0,725 & 0,722 \\
\hline
\end{tabular}

Continua...

7 De acordo com Krugman e Obstfeld (2011), após uma depreciação, os valores de importação e exportação ainda refletem os contratos já estipulados com base na antiga taxa de câmbio real, pois considera-se a existência dos contratos de câmbio e a defasagem na tomada de decisão dos agentes. 
Conclusão.

\begin{tabular}{|c|c|c|c|c|c|c|c|c|}
\hline $\begin{array}{l}\text { Variável } \\
\text { dependente (X) }\end{array}$ & \multicolumn{4}{|c|}{ DLEXPORT } & \multicolumn{4}{|c|}{ DLVAD_CGV } \\
\hline $\begin{array}{l}\text { Teste de Haus- } \\
\text { man }\end{array}$ & 0,000 & 0,001 & 0,000 & 0,000 & 0,000 & 0,001 & 0,000 & 0,000 \\
\hline
\end{tabular}

Fonte: Elaboração própria a partir do software Stata 13.

Nota: Erros padrões robustos entre parênteses; *, ** e *** indicam significância estatística a $10 \%, 5 \%$ e $1 \%$, respectivamente. Todas os modelos foram estimados por efeitos aleatórios (EA) e fixos, após foi realizado o teste de Hausman, que informa qual método é mais consistente (hipótese nula: os estimadores por EA são consistentes).

Tabela 2 - Resultado das estimações pelo método de dados em painel dinâmico (system GMM)

\begin{tabular}{|c|c|c|c|c|c|c|c|c|}
\hline \multirow{2}{*}{\begin{tabular}{l|}
$\begin{array}{l}\text { Variável } \\
\text { dependente }(\mathbf{X})\end{array}$ \\
Modelos \\
\end{tabular}} & \multicolumn{4}{|c|}{ DLEXPORT } & \multicolumn{4}{|c|}{ DLVAD_CGV } \\
\hline & 1 & 2 & 3 & 4 & 1 & 2 & 3 & 4 \\
\hline Dependente $(-1)$ & $\begin{array}{l}0,126 \\
(0,093)\end{array}$ & $\begin{array}{l}0,120 \\
(0,119)\end{array}$ & $\begin{array}{l}0,206^{*} \\
(0,117)\end{array}$ & $\begin{array}{l}0,223^{*} \\
(0,120)\end{array}$ & $\begin{array}{l}0,137 \\
(0,109)\end{array}$ & $\begin{array}{l}0,070 \\
(0,133)\end{array}$ & $\begin{array}{l}0,195^{*} \\
(0,103)\end{array}$ & $\begin{array}{r}0,220 * * \\
(0,104)\end{array}$ \\
\hline DLPIB_Externo & $\begin{array}{l}\mathbf{0 , 3 2 1} \text { *** } \\
(0,085)\end{array}$ & $\begin{array}{l}\mathbf{0 , 4 1 6 * * *} \\
(0,080)\end{array}$ & $\begin{array}{l}0,301 * * * \\
(0,094)\end{array}$ & $\begin{array}{l}0,285^{* * *} \\
(0,103)\end{array}$ & $\begin{array}{l}0,321 * * * \\
(0,080)\end{array}$ & $\begin{array}{l}0,405^{* * *} \\
(0,104)\end{array}$ & $\begin{array}{l}0,291 * * \\
(0,118)\end{array}$ & $\begin{array}{l}0,217^{* * *} \\
(0,100)\end{array}$ \\
\hline LTCREF (-1) & $\begin{array}{l}\mathbf{- 0 , 1 5 6 * * *} \\
(0,048)\end{array}$ & & & & $\begin{array}{l}\mathbf{- 0 , 1 8 9 * * *} \\
(0,041)\end{array}$ & & & \\
\hline VOLAT & & $\begin{array}{l}-\mathbf{0 , 3 5 3} \\
(0,343)\end{array}$ & & & & $\begin{array}{l}\mathbf{- 0 , 1 5 7} \\
(0,135)\end{array}$ & & \\
\hline DESAL (-1) & & & $\begin{array}{r}-0,132^{* * *} \\
(0,066)\end{array}$ & & & & $\begin{array}{l}-0,138 \\
(0,119)\end{array}$ & \\
\hline DESAL_Amp (-1) & & & & $\begin{array}{l}-0,329^{*} \\
(0,175)\end{array}$ & & & & $\begin{array}{l}-0,018 \\
(0,277)\end{array}$ \\
\hline DUCRISE09 & $\begin{array}{l}-\mathbf{0 , 3 3 3} 4^{* * *} \\
(0,035) \\
\end{array}$ & $\begin{array}{l}-\mathbf{0 , 3 1 8 * * *} \\
(0,042)\end{array}$ & $\begin{array}{l}-\mathbf{0 , 2 8 7 * * *} \\
(0,019)\end{array}$ & $\begin{array}{l}\mathbf{- 0 , 2 8 6 * * *} \\
(0,023)\end{array}$ & $\begin{array}{l}-\mathbf{0 , 3 8 3 * * *} \\
(0,020)\end{array}$ & $\begin{array}{l}-\mathbf{0 , 3 8 2} * * * \\
(0,020)\end{array}$ & 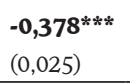 & $\begin{array}{l}-0,393^{* * *} \\
(0,025)\end{array}$ \\
\hline $\mathrm{AR}(2)$ & 0,629 & 0,622 & 0,391 & 0,369 & 0,584 & 0,866 & 0,388 & 0,385 \\
\hline Hansen & 0,295 & 0,454 & 0,379 & 0,361 & 0,580 & 0,406 & 0,350 & 0,345 \\
\hline Dif. Hansen & 0,686 & 0,410 & 0,333 & 0,457 & 0,435 & 0,838 & 0,376 & 0,241 \\
\hline Número de países & 59 & 59 & 59 & 59 & 59 & 59 & 59 & 59 \\
\hline $\begin{array}{l}\text { Número de } \\
\text { instrumentos }\end{array}$ & 63 & 65 & 63 & 63 & 63 & 65 & 63 & 63 \\
\hline
\end{tabular}

Fonte: Elaboração própria a partir do software Stata 13.

Nota: Erros padrões robustos entre parênteses; * ** $\mathrm{e}$ *** indicam significância estatística a $10 \%, 5 \%$ e 1\%, respectivamente. Todos os modelos foram estimados por system GMM two-step e controlam a proliferação de instrumentos pelo comando laglimits (2 2). 
Tabela 3 - Resultado das estimações pelo método de dados em painel dinâmico (difference GMM)

\begin{tabular}{|c|c|c|c|c|c|c|c|c|}
\hline \multirow{2}{*}{$\begin{array}{l}\begin{array}{l}\text { Variável de- } \\
\text { pendente (X) }\end{array} \\
\text { Modelos } \\
\end{array}$} & \multicolumn{4}{|c|}{ DLEXPORT } & \multicolumn{4}{|c|}{ DLVAD_CGV } \\
\hline & 1 & 2 & 3 & 4 & 1 & 2 & 3 & 4 \\
\hline $\begin{array}{l}\text { Dependente } \\
(-1)\end{array}$ & $\begin{array}{l}-0,091^{*} \\
(0,054)\end{array}$ & $\begin{array}{l}-0,070 \\
(0,045)\end{array}$ & $\begin{array}{l}-0,060 \\
(0,055)\end{array}$ & $\begin{array}{l}-0,047 \\
(0,055)\end{array}$ & $\begin{array}{c}-0,147^{* * *} \\
(0,053)\end{array}$ & $\begin{array}{c}-0,116^{* *} \\
(0,048)\end{array}$ & $\begin{array}{l}-0,119^{* *} \\
(0,049)\end{array}$ & $\begin{array}{c}-0,125^{* * *} \\
(0,043)\end{array}$ \\
\hline DLPIB_Externo & $\begin{array}{c}0,373 * * * \\
(0,132)\end{array}$ & $\begin{array}{c}0,377^{* * *} \\
(0,129)\end{array}$ & $\begin{array}{c}0,357 * * \\
(0,115)\end{array}$ & $\begin{array}{l}0,300^{* *} \\
(0,119)\end{array}$ & $\begin{array}{c}0,391 * * * \\
(0,109)\end{array}$ & $\begin{array}{l}0,441^{* *} \\
(0,181)\end{array}$ & $\begin{array}{c}0,383^{* * *} \\
(0,137)\end{array}$ & $\begin{array}{l}0,302^{*} \\
(0,157)\end{array}$ \\
\hline LTCREF (-1) & $\begin{array}{l}-0,166^{* *} \\
(0,070)\end{array}$ & & & & $\begin{array}{l}-0,197^{*} \\
(0,109)\end{array}$ & & & \\
\hline VOLAT & & $\begin{array}{c}-\mathbf{0 , 2 3 3 * * *} \\
(0,074)\end{array}$ & & & & $\begin{array}{l}-\mathbf{0 , 0 4 0} \\
(0,183)\end{array}$ & & \\
\hline $\operatorname{DESAL}(-1)$ & & & $\begin{array}{c}-0,206^{* * *} \\
(0,062)\end{array}$ & & & & $\begin{array}{l}-0,120^{*} \\
(0,068)\end{array}$ & \\
\hline $\begin{array}{l}\text { DESAL_Amp } \\
(-1)\end{array}$ & & & & $\begin{array}{c}-0,286^{* * *} \\
(0,109)\end{array}$ & & & & $\begin{array}{l}-0,003 \\
(0,191)\end{array}$ \\
\hline DUCRISE09 & $\begin{array}{c}-0,287^{* * *} \\
(0,023) \\
\end{array}$ & $\begin{array}{c}-0,287^{* * *} \\
(0,019)\end{array}$ & $\begin{array}{c}-0,287^{* * *} \\
(0,020)\end{array}$ & $\begin{array}{c}-0,292^{* * *} \\
(0,020)\end{array}$ & $\begin{array}{c}-0,395^{* * *} \\
(0,021) \\
\end{array}$ & $\begin{array}{c}-0,394^{* * *} \\
(0,027)\end{array}$ & $\begin{array}{c}-0,399^{* * *} \\
(0,024)\end{array}$ & $\begin{array}{c}-0,411^{* * *} \\
(0,023)\end{array}$ \\
\hline $\mathrm{AR}(2)$ & 0,283 & 0,455 & 0,457 & 0,422 & 0,142 & 0,235 & 0,239 & 0,175 \\
\hline Hansen & 0,381 & 0,565 & 0,352 & 0,599 & 0,552 & 0,435 & 0,389 & 0,528 \\
\hline $\begin{array}{l}\text { Número de } \\
\text { países }\end{array}$ & 59 & 59 & 59 & 59 & 59 & 59 & 59 & 59 \\
\hline $\begin{array}{l}\text { Número de } \\
\text { instrumentos }\end{array}$ & 65 & 67 & 65 & 65 & 65 & 67 & 65 & 65 \\
\hline
\end{tabular}

Fonte: Elaboração própria a partir do software Stata 13.

Nota: Erros padrões robustos entre parênteses; *, ** e *** indicam significância estatística a $10 \%, 5 \%$ e $1 \%$, respectivamente. Todos os modelos foram estimados por difference GMM twostep e controlam a proliferação de instrumentos pelo comando laglimits (2 1).

Primeiramente, os resultados das estimações indicam que todos os coeficientes estimados possuem sinais com coerência econômica. Pode-se observar, na estimação por EF, que os coeficientes do PIB_Externo na variável dependente EXPORT são maiores e apresentaram significância estatística de 1\% nos modelos 1 e 2 e de $5 \%$ nos modelos 3 e 4 . Por outro lado, o impacto do PIB_Externo nas exportações vinculadas às CGV, além de possuir coeficientes de menor impacto em relação à variável EXPORT, não apresentou significância estatística em nenhum dos quatro modelos.

Com relação aos coeficientes da variável TCREF, de maneira oposta ao predomínio dos resultados da literatura empírica, a elasticidade-preço das exportações vinculadas ao fenômeno das CGV são menores em relação às exportações convencionais. Uma apreciação de $10 \%$ da TCREF gera um efeito negativo de $1,8 \%$ na variação da taxa de crescimento das exportações tradicionais e de 1,4\% na 
variação da taxa de crescimento do VAD_CGV. Além disso, o coeficiente da TCREF para as duas variáveis dependentes apresenta $1 \%$ de significância estatística.

Os dois coeficientes da VOLAT (estatisticamente significantes a 1\%) apontam uma diminuição percentual de aproximadamente $38 \%$ entre as volatilidades de EXPORT e VAD_CGV, resultado análogo ao encontrado por Sato e Zhang (2018). Caso haja um aumento de 10 pontos percentuais na volatilidade cambial, a variação da taxa de crescimento das exportações convencionais será afetada negativamente em $2,5 \%$, enquanto a variação da taxa de crescimento das exportações associada às CGV será de $1,59 \%$.

Com relação aos coeficientes da variável DESAL para EXPORT e VAD_CGV, ambos apresentaram significância estatística a $1 \%$ e valores, respectivamente, de -0,209 e -0,148. Já a variável DESAL_Amp revelou coeficientes de -0,296 e -0,128 para as variáveis EXPORT e VAD_CGV, respectivamente. Esses resultados indicam que uma sobrevalorização em torno de uma TCREF de equilíbrio gera impactos negativos nas exportações, porém em magnitude e significância estatística menores quando consideradas as exportações vinculadas às CGV.

As regressões pelos métodos system e difference GMM apresentaram nas exportações relacionadas às CGV menor sensibilidade às alterações da TCREF em comparação à sensibilidade das exportações convencionais às mudanças da TCREF, resultado oposto ao identificado na regressão por EF, que apresenta maior elasticidade-preço das exportações relacionas às CGV em relação à elasticidade-preço das exportações convencionais. Esses resultados são condizentes com os demonstrados pelos trabalhos de Arbatali e Hong (2016) e de De Soyres et al. (2018) Para os coeficientes de VOLAT, no método system GMM, ocorreu uma diminuição percentual de 55\% entre as respostas de EXPORT e VAD_CGV a aumentos da volatilidade cambial, resultado próximo ao encontrado por Sato e Zhang (2018). No entanto, nesse método, a VOLAT não apresentou impactos estatisticamente significantes nas duas variáveis dependentes. Já em relação ao método difference GMM, a VOLAT apresentou significância estatística de 1\% e coeficiente de -0,233 para a variável EXPORT e, para a variável VAD_CGV, apresentou um coeficiente pequeno e nenhuma significância estatística. Esses resultados indicam que um aumento de 10 pontos percentuais na volatilidade gera um impacto negativo de $2,3 \%$ na variação da taxa de crescimento das exportações convencionais e que a variável VOLAT não possui significância estatística para explicar a variação da taxa de crescimento das exportações relacionadas às CGV.

A DESAL apresentou significância estatística para explicar a EXPORT a 5\% e nenhuma significância estatística para a VAD_CGV no método system GMM. No caso do difference GMM, a DESAL revelou significância estatística de 1\% para as exportações tradicionais e nenhuma significância estatística para as exportações relacionadas às CGV. Quanto à variável DESAL_Amp, os dois métodos de painel 
dinâmico apontaram que uma sobrevalorização provoca impactos negativos nas exportações, porém em magnitude menor quando consideradas as exportações vinculadas às CGV. Com relação aos coeficientes referentes à crise do subprime (DUCRISE09), verifica-se que as exportações a jusante nas CGV foram mais afetadas do que as exportações convencionais.

Por fim, os resultados do teste AR (2) indicam que há ausência de correlação serial de segunda ordem e demonstra que as estimações são consistentes. Os testes de validade dos instrumentos apresentaram $p$-valores em níveis adequados em todos os modelos, ou seja, os instrumentos são válidos e não correlacionados com o termo de erro, eliminado o viés de endogeneidade. Soma-se a isso o fato de que o número de instrumentos não excedeu demasiadamente o número de países da amostra, reforçando a não proliferação de instrumentos.

Analisando-se conjuntamente os resultados dos três painéis estimados, pode-se concluir que: a) a hipótese de que as elasticidades-preço das exportações relacionadas às CGV são maiores em relação às exportações convencionais confirma-se; b) assegura-se a hipótese de que a volatilidade cambial possui menor ou nenhum impacto nas exportações vinculadas às CGV, apresentando ter, em média, uma diminuição percentual de 50\% entre as respostas de EXPORT e VAD_CGV com aumentos da volatilidade cambial; c) com relação ao desalinhamento cambial, os três métodos estimados confirmaram que o desalinhamento possui maior impacto nas exportações tradicionais relativamente ao efeito sobre as exportações relacionadas às CGV e que a DESAL_Amp corroborou esses resultados, apresentando resultados e conclusões ainda mais robustas; d) não é factível confirmar que maiores participações a jusante no total das exportações demonstram menor elasticidade-renda das exportações, pois os coeficientes em dois dos três métodos não apresentaram divergências significativas para explicar as duas variáveis dependentes. Além disso, constatou-se que as exportações vinculadas às CGV obtiveram efeitos mais prejudiciais em relação às exportações convencionais por consequências da crise financeira em 2008.

\section{Considerações Finais}

O objetivo deste trabalho consistiu em realizar uma contribuição e investigação empírica acerca das CGV e sua influência na relação entre a taxa de câmbio e as exportações. Tal contribuição se torna relevante à medida que se verifica uma intensificação desse fenômeno ao redor do mundo, que tem modificado as relações econômicas do comércio internacional, sendo a dinâmica entre taxa de câmbio e os fluxos comerciais uma delas.

Para o alcance dos objetivos aqui propostos, foram estimados quatro modelos a partir de três métodos de dados em painel, contendo 59 países no período 
de 2000 a 2011, um painel estático (EF) e dois em painel dinâmico (system GMM e difference GMM), visando observar a diferença entre as exportações tradicionais e as exportações a jusante relacionadas às CGV em resposta à taxa de câmbio real efetiva em três conceitos: nível, volatilidade e desalinhamento. Além disso, foram incluídos aos modelos uma proxy de renda estrangeira para verificar as elasticidades-renda das duas exportações analisadas e uma dummy para verificar o impacto da crise do subprime nas duas variáveis dependentes citadas.

Os resultados econométricos confirmaram que exportações para frente nas CGV possuem elasticidade-preço das exportações maiores em relação à elasticidade-preço das exportações tradicionais. Reitera-se a hipótese de que aumentos da volatilidade cambial possuem menores impactos adversos nas exportações vinculadas às $\mathrm{CGV}$ em relação às exportações tradicionais. Pode-se indicar que o desalinhamento, em torno de uma taxa de câmbio real de equilíbrio, apresentou maior relevância para explicar o crescimento das exportações convencionais em comparação ao valor adicionado doméstico associado às CGV. Dessa maneira, pode-se afirmar que países que possuem maior participação a jusante nas CGV estão menos sujeitos a impactos negativos (positivos) para períodos de aumento (diminuição) da volatilidade cambial e a impactos adversos (favoráveis) de uma sobrevalorização (desvalorização) em torno de uma variável TCREF de equilíbrio. Por fim, não foi possível afirmar que há diferenças substanciais nas elasticidades-renda das exportações e constatou-se que a crise do subprime gerou efeitos negativos mais proeminentes nas exportações relacionadas às CGV.

Finalmente, este trabalho permitiu confirmar hipóteses anteriormente apresentadas e conceder novas respostas acerca da relação entre taxa de câmbio e exportações no contexto das CGV. Dessa forma, atentando à expansão da integração nas redes globais de produção pelo mundo, torna-se cada vez mais relevante traçar estratégias para a inserção comercial e produtiva nas CGV a partir de políticas públicas orientadas para o desenvolvimento de tecnologia, instraestrutura e eficiência institucional, assim como realizar uma administração adequada da taxa de câmbio real efetiva, de maneira que o câmbio contenha menos volatilidade e seu desalinhamento apresente efetividade para o avanço do desempenho e qualidade das exportações. 


\section{Referências}

AHMED, S.; APPENDINO, M.; RUTA, M. Depreciations without exports? Global value chains and the exchange rate elasticity of exports. World Bank Policy Research Working Paper Series, n. $7390,2015$.

ALFARO, L.; CUNAT, A.; FADINGER, H.; LIU, Y. The real exchange rate, innovation and productivity: regional heterogeneity, asymmetries and hysteresis. NBER Working Paper, $\mathrm{n}$. 24633, 2019.

AKAIKE, H. A. Bayesian analysis of the minimum AIC procedure. Annals of the Institute of Statistical Mathematics, v. 30, n.1, p. 9-14, 1978.

ARBATLI, E.; HONG, G. H. Singapore's export elasticities: a disaggregated look into the role of global value chains and economic Complexity. IMF Working Paper 16/52. International Monetary Fund, 2016.

ARELLANO, M.; BOND, S. Some Tests of Specification for Panel Data: Monte Carlo Evidence and an Application to Employment Equations. Review of Economics Studies, v. 58, sin. 2, p. 277-297, 1991. Disponível em: http://www.jstor.org/stable/2297968. Acesso em: 10 ago. 2018.

ARELLANO, M.; BOVER, O. Another look at the instrumental variable estimation of errorcomponents models. Journal of Econometrics, v. 68, p. 29-52, 1995. Disponível em: https:// doi.org/10.1016/0304-4076(94)01642-D. Acesso em: 10 ago. 2018.

AUBOIN, M.; RUTA, M. The Relationship between Exchange Rates and International Trade: A Review of Economic Literature. WTO Satff Working Papers, n. 17, 2011. Disponível em: http://dx.doi.org/10.2139/ssrn.1955847. Acesso em: 22 set. 2018.

BALDWIN, R. Global Supply Chains: Why They Emerged, Why They Matter, and Where They Are Going. CPER Discussion Papers, n. 9103, 2012.

BANGA, K. Impact of global value chains on employment in India. Journal of Economic Integration, v. 31, n. 3, p. 631-673, 2016. Disponível em: https://doi.org/10.11130/ jei.2016.31.3.631. Acesso em: 28 set. 2018.

BAYOUMI, T.; SALGADO, R.; MILLS, M. Trade interconnectedness: the world with global value chains. IMF Policy Paper Series, 2013.

BLUNDELL, R.; BOND, S. Initial conditions and moment restrictions in dynamic panel data models. Journal of Econometrics, v. 87, p. 115-143, 1998. Disponível em: https://10.0.3.248/ S0304-4076(98)00009-8. Acesso em: 11 ago. 2018.

BRESSER-PEREIRA, L. C. O Brasil e o novo desenvolvimentismo. Interesse nacional, p. 7685, 2011.

BRESSER-PEREIRA, L. C.; OREIRO, J.L.; MARCONI, N. Macroeconomia desenvolvimentista: teoria e política econômica do novo desenvolvimentismo. Rio de Janeiro: Elsevier Brasil, 2017. 
CHENG, K. C.; HONG, G.H; SENEVIRATNE, D.; VAN ELKAN, R. Rethinking the Exchange Rate Impact on Trade in a World with Global Value Chains. International Economic Journal, v. 30, n. 2, p. 204-216, 2016. Disponível em: https://doi.org/10.1080/10168737.2016.114841 8. Acesso em: 25 out. 2018.

CLARK, P.; MACDONALD, R. Exchange rates and economic fundamentals: a methodological comparison of BEERs and FEERs. In: MACDONALD, R.; STEIN, J. L. Equilibrium Exchange Rates. Boston: Kluwer, 1999. p. 285-322.

CRONOVICH, R.; GAZEL, R. Do exchange rates and foreign incomes matter for exports at the state level? Journal of Regional Science, v. 38, n. 4, p. 639-657, 1998.

DE SOYRES, F.; FROHM, E.; GUNNELLA, V.; PAVLOVA, E. Bought, sold and bought again: the impact of complex value chains on export elasticities. World Bank Policy Research Working Paper, n. 8535, 2018. Disponível em: https://doi.org/10.1596/1813-9450-8535. Acesso em: 08 out. 2018.

DOLLAR, D.; GE, Y.; YU, X. Institutions Quality and Participation in Global Value Chains. In: WORD BANK GROUP. Global Value Chain Development Report 2017: Measuring and Analyzing the Impact of GVCs on Economic Development. Washington: World Bank, 2017. p. 161-173.

ESTEVADEORDAL, A.; BLYDE, J.; SUOMINEN, K. Are Global Value Chains Really Global? Policies to Accelerate Countries' Access to International Production Networks. E15Initiative, 2013.

FARUQEE, H.; ISARD, P.; MASSON, P.R. A macroeconomic balance framework for estimating equilibrium exchange rates. In: MACDONALD, R.; STEIN, J. L. Equilibrium Exchange Rates. Boston: Kluwer, 1999. p. 103-133.

GEREFFI, G. The organization of buyer-driven global commodity chains: how U.S. retailers shape overseas production networks. In: GEREFFI, G.; KORZENIEWICZ, M. Commodity Chains and Global Capistalism. London: Praeger, 1994. p. 95-122.

GEREFFI, G. International trade and industrial upgrading in the apparel commodity chain. Journal of International Economics, v. 48, n. 1, p. 37-70, 1999. Disponível em: https://doi. org/10.1016/S0022-1996(98)00075-0. Acesso em: 10 abr. 2018.

GEREFFI, G.; HUMPHREY, J.; STURGEON, T. The governance of global value chains. Review of International Political Economy, v. 12, n. 1, p. 78-104, 2005. Disponível em: https://doi. org/10.1080/09692290500049805. Acesso em: 10 abr. 2018.

HADDAD, M.; PANCARO, C. Can real exchange rate undervaluation boost exports and growth in developing countries? Yes, but not for long. Economic Premise, n. 20, 2010.

HERMIDA, C. C. Padrão de especialização comercial e crescimento econômico: uma análise sobre o brasil no contexto da fragmentação da produção e das cadeias globais de valor. 2016. Tese (Doutorado em Economia) - Instituto de Economia e Relações Internacionais, Universidade Federal de Uberlândia, Uberlândia, 2016. 
HUMPHREY, J.; SCHMITZ, H. How does insertion in global value chains affect upgrading in industrial clusters? Regional Studies, v. 36, n. 9, p. 1017-1027, 2002. Disponível em: http:// dx.doi.org/10.1080/0034340022000022198. Acesso em: 05 out. 2018.

ISARD, P.; FARUQEE, H. Exchange Rate Assessment: Extension of the Macroeconomic Balance Approach. IMF Occasional Papers, n. 167, 1998.

JOHNSON, R. C.; NOGUERA, G. A Portrait of Trade in Value-Added over Four Decades. The Review of Economics and Statistics, v. 99, n. 5, p. 896-911, 2017. Disponível em: http:// dx.doi.org/10.1162/REST_a_00665. Acesso em: 08 out. 2018.

JOHNSON, R.; NOGUERA, G. Fragmentation and Trade in Value Added over Four Decades. NBER Working Paper, n. 18186, 2012. Disponível em: http://dx.doi.org/10.3386/ w18186. Acesso em: 12 abr. 2018.

KANG, J. W.; DAGLI, S. International trade and exchange rates. Journal of Applied Economics, v. 21, n. 1, p. 84-105, 2018. Disponível em: http://dx.doi.org/10.1080/15140326.2018.152 6878. Acesso em: 22 ago. 2018.

KOOPMAN, R.; POWERS, W.; WHANG, Z.; WEI, S.W. Give credit where credit is due: tracing value added in global production chains. NBER Working Paper, n. 16426, 2010. Disponível em: http://dx.doi.org/10.3386/w16426. Acesso em: 02 mai. 2018.

KOOPMAN, R.; WANG, Z.; WEI, S.-J. Tracing value-added and double counting in gross exports. NBER Working Paper, n. 18579, 2012. Disponível em: http://dx.doi.org/10.3386/ w18579. Acesso em: 15 abr. 2018.

KRUGMAN, P.; OBSTFELD, M. Economia Internacional: Teoria e Política. 5. ed. São Paulo: Pearson Education do Brasil, 2011.

NICITA, A. Exchange rates, international trade and trade policies. Policy Issues in International Trade and Commodities, n. 56, 2013. Disponível em: http://dx.doi.org/10.1016/j.inteco.2013.10.003. Acesso em: 28 abr. 2018.

OECD. Interconnected economies: benefiting from global value chains. Synthesis Report. Paris: OECD, 2013. Disponível em: http://dx.doi.org/10.1787/9789264189560-en. Acesso em: 05 abr. 2018 .

OECD. Trade in Value Added (TiVA). OECD's Inter-Country Input-Output (ICIO) Database. Paris: OECD, 2013. Disponível em: https://stats.oecd.org/Index.aspx?DataSetCode=TIVA_2016_ C1. Acesso em: 27 abr. 2018.

ROODMAN, D. How to do Xtabond2: An Introduction to Difference and System GMM in Stata. The Stata Journal, v. 9, n. 1, p. 86-136, 2009a. Disponível em: http://dx.doi.org/10.2139/ ssrn.982943. Acesso em: 25 out. 2018.

ROODMAN, D. A note on the theme of too many instruments. Oxford Bulletin of Economics and Statistics, v. 71, n. 1, p. 135-158, 2009b. Disponível em: http://dx.doi.org/10.1111/j.14680084.2008.00542.x. Acesso em: 25 out. 2018. 
RUBÍNOVÁ, S. The impact of new regionalism on global value chains participation. FREIT Working Papers, 2017.

SATO, K.; ZHANG, S. Exchange rate volatility, exports and global value chains. RIETI Discussion Paper Series, 2018.

SCHWARZ, G. Estimating the dimension of a model. Annals of Statistics, v. 6, n.2, p. 461-464, 1978.

STEIN, J. L. The natural real exchange rate of the US dollar and determinants of capital flows. In: WILLIAMSON, J. Estimating Equilibrium Exchange Rates. Washington D.C.: Institute for International Economics, p. 133-176, 1994.

STEIN, J. L. The fundamental determinants of the real exchange rate of the U.S.dollar relative to other G-7 countries. IMF Working Paper, n. 81, 1995.

STEIN, J. L. The equilibrium real exchange rate of the euro: an evaluation of research. CESifo Economic Studies, v. 43, n. 3, p. 349-381, 2002.

VIEIRA, F. V.; MACDONALD, R. A panel data investigation of real exchange rate misalignment and growth. Estudos Econômicos, v. 42, n. 3, p. 433-456, 2012. Disponível em: http:// dx.doi.org/10.1590/S0101-41612012000300001. Acesso em: 20 abr. 2018.

VIEIRA, F. V.; MACDONALD, R. Exchange rate volatility and exports: a panel data analysis. Journal of Economic Studies, v. 43, n. 2, p. 203-221, 2016. Disponível em: http://dx.doi. org/10.1108/JES-05-2014-0083. Acesso em: 20 abr. 2018.

WILLIAMSON, J. The Exchange Rate System. Institute for International Economics, Policy Analyses in International Economics, n. 5, 1983.

WILLIAMSON, J. Estimates of FEERs. In: WILLIAMSON, J. Estimating Equilibrium Exchange Rates. Washington D.C.: Institute for International Economics, p. 177-244, 1994.

WOOLDRIDGE, J. M. Applications of Generalized Method of Moments Estimation. Journal of Economic Perspectives, v. 15, n. 4, p. 87-100, 2001. Disponível em: http://dx.doi. org/10.1257/jep.15.4.87. Acesso em: 25 out. 2018. 


\section{Apêndice A}

Quadro 1 - Países presentes na amostra e seus respectivos modelos de seleção estimados por $\mathrm{ARCH} / \mathrm{GARCH}$

\begin{tabular}{|c|c|c|c|}
\hline Países & $\begin{array}{c}\text { Modelo de seleção } \\
\text { ARMA (n, i) GARCH } \\
(\mathrm{p}, \mathrm{q})\end{array}$ & Países & $\begin{array}{c}\text { Modelo de seleção } \\
\text { ARMA }(n, i) \operatorname{GARCH}(p, q)\end{array}$ \\
\hline África do Sul & $\operatorname{ARMA}(1,1)-\operatorname{GARCH}(1,1)$ & Índia & $\operatorname{ARMA}(1,1)-\mathrm{ARCH}(1)$ \\
\hline Alemanha & $\mathrm{AR}(1)-\mathrm{ARCH}(1)$ & Indonésia & $\operatorname{ARMA}(4,3)-\mathrm{ARCH}(2)$ \\
\hline Arábia Saudita & $\mathrm{AR}(2)-\mathrm{ARCH}(1)$ & Irlanda & $\mathrm{AR}(1)-\mathrm{ARCH}(1)$ \\
\hline Argentina & $\operatorname{AR}(2)-\operatorname{GARCH}(1,1)$ & Islândia & $\operatorname{AR}(2)-\operatorname{GARCH}(1,1)$ \\
\hline Austrália & $\mathrm{AR}(2)-\mathrm{GARCH}(1,1)$ & Israel & $\operatorname{AR}(2)-\operatorname{GARCH}(1,1)$ \\
\hline Áustria & $\operatorname{AR}(1)-G A R C H(1,1)$ & Itália & $\operatorname{AR}(2)-\operatorname{GARCH}(1,1)$ \\
\hline Bélgica & $\mathrm{AR}(1)-\mathrm{ARCH}(1)$ & Japão & $\mathrm{AR}(1)-\mathrm{ARCH}(1)$ \\
\hline Brasil & $\mathrm{AR}(2)-\mathrm{ARCH}(1)$ & Letônia & $\operatorname{ARMA}(2,2)-\operatorname{GARCH}(1,1)$ \\
\hline Bulgária & $\mathrm{AR}(2)-\mathrm{ARCH}(1)$ & Lituânia & $\operatorname{AR}(1)-G A R C H(1,1)$ \\
\hline Canadá & $\mathrm{AR}(1)-\mathrm{ARCH}(1)$ & Luxemburgo & $\operatorname{AR}(1)-\operatorname{GARCH}(1,1)$ \\
\hline Chile & $\mathrm{AR}(1)-\mathrm{ARCH}(1)$ & Malásia & $\operatorname{AR}(1)-G A R C H(1,1)$ \\
\hline China & $\mathrm{AR}(1)-\mathrm{ARCH}(1)$ & Malta & $\operatorname{ARMA}(2,2)-\operatorname{GARCH}(1,1)$ \\
\hline Chipre & $\operatorname{ARMA}(2,1)-\operatorname{ARCH}(1)$ & Marrocos & $\operatorname{ARMA}(3,3)-\operatorname{GARCH}(1,1)$ \\
\hline Colômbia & $\operatorname{ARMA}(2,1)-\mathrm{GARCH}(1,1)$ & México & $\mathrm{AR}(1)-\mathrm{ARCH}(1)$ \\
\hline Coreia do Sul & $\operatorname{ARMA}(2,1)-\mathrm{GARCH}(1,1)$ & Noruega & $\mathrm{AR}(1)-\mathrm{ARCH}(1)$ \\
\hline Costa Rica & $\mathrm{AR}(2)-\mathrm{ARCH}(1)$ & Nova Zelândia & $\operatorname{AR}(1)-\operatorname{GARCH}(1,1)$ \\
\hline Croácia & $\operatorname{ARMA}(1,2)-\mathrm{ARCH}(1)$ & Peru & $\mathrm{AR}(1)-\mathrm{ARCH}(1)$ \\
\hline Dinamarca & $\mathrm{AR}(1)-\mathrm{ARCH}(1)$ & Polônia & $\mathrm{AR}(1)-\mathrm{ARCH}(1)$ \\
\hline Eslováquia & $\mathrm{AR}(1)-\mathrm{ARCH}(1)$ & Portugal & $\operatorname{ARMA}(1,1)-\mathrm{ARCH}(1)$ \\
\hline Eslovênia & $\operatorname{ARMA}(2,1)-\mathrm{ARCH}(1)$ & Reino Unido & $\operatorname{ARMA}(2,1)-\mathrm{ARCH}(1)$ \\
\hline Espanha & $\mathrm{AR}(2)-\mathrm{GARCH}(1,1)$ & República Tcheca & $\mathrm{AR}(1)-\mathrm{ARCH}(1)$ \\
\hline Estados Unidos & $\mathrm{AR}(1)-\mathrm{ARCH}(1)$ & Romênia & $\mathrm{AR}(1)-\mathrm{ARCH}(1)$ \\
\hline Estônia & $\operatorname{AR}(2)-\operatorname{GARCH}(1,1)$ & Rússia & $\mathrm{AR}(1)-\mathrm{ARCH}(1)$ \\
\hline Filipinas & $\mathrm{AR}(2) \mathrm{ARCH}(1)$ & Singapura & $\operatorname{ARMA}(1,1)-\operatorname{ARCH}(1)$ \\
\hline Finlândia & $\mathrm{AR}(2)-\mathrm{ARCH}(1)$ & Suécia & $\mathrm{AR}(1)-\mathrm{ARCH}(1)$ \\
\hline França & $\mathrm{AR}(2)-\mathrm{ARCH}(1)$ & Suíça & $\mathrm{AR}(1)-\mathrm{ARCH}(2)$ \\
\hline Grécia & $\operatorname{ARMA}(1,1)-\mathrm{ARCH}(1)$ & Tailândia & $\operatorname{ARMA}(2,2)-\mathrm{ARCH}(2)$ \\
\hline Holanda & $\operatorname{AR}(2)-\operatorname{GARCH}(1,1)$ & Tunísia & $\operatorname{ARMA}(3,3)-\mathrm{ARCH}(1)$ \\
\hline Hong Kong & $\mathrm{AR}(1)-\mathrm{ARCH}(1)$ & Turquia & $\mathrm{AR}(3)-\mathrm{ARCH}(1)$ \\
\hline Hungria & $\mathrm{AR}(1)-\mathrm{ARCH}(2)$ & & \\
\hline
\end{tabular}

Fonte: Elaboração própria a partir do software Eviews 10.

Nota: $n$ é a ordem autoregressiva e i é a ordem da média móvel da DLREER; $(p, q)$ refere-se à presença de um termo GARCH autorregressivo de ordem $q$ e de um termo $\mathrm{ARCH}$ de média móvel de ordem $p$. 
Quadro 2 - Teste de raiz unitária em painel das variáveis utilizadas nos modelos econométricos

\begin{tabular}{|c|c|c|c|c|}
\hline Variáveis & Método & Statistic & Probabilidade & Resultado \\
\hline \multirow{4}{*}{ DLEXPORT } & Levin, Lin e Chu & $-20,644$ & 0.0000 & Estacionária \\
\hline & Im, Pesaran e Shin & $-11,855$ & 0.0000 & Estacionária \\
\hline & $\mathrm{ADF}$ & 340,386 & 0.0000 & Estacionária \\
\hline & $\mathrm{PP}$ & 397,086 & 0.0000 & Estacionária \\
\hline \multirow{4}{*}{ DLVAD_CGV } & Levin, Lin e Chu & $-20,993$ & 0.0000 & Estacionária \\
\hline & Im, Pesaran e Shin & $-12,851$ & 0.0000 & Estacionária \\
\hline & $\mathrm{ADF}$ & 365,998 & 0.0000 & Estacionária \\
\hline & PP & 447,84 & 0.0000 & Estacionária \\
\hline \multirow{4}{*}{ DLPIB_Externo } & Levin, Lin e Chu & $-20,286$ & 0.0000 & Estacionária \\
\hline & Im, Pesaran e Shin & $-13,291$ & 0.0000 & Estacionária \\
\hline & $\mathrm{ADF}$ & 379,269 & 0.0000 & Estacionária \\
\hline & PP & 392,871 & 0.0000 & Estacionária \\
\hline \multirow{4}{*}{ LTCREF } & Levin, Lin e Chu & $-9,634$ & 0.0000 & Estacionária \\
\hline & Im, Pesaran e Shin & $-3,621$ & 0.0001 & Estacionária \\
\hline & $\mathrm{ADF}$ & 174,988 & 0.0005 & Estacionária \\
\hline & PP & 184,02 & 0.0001 & Estacionária \\
\hline \multirow{4}{*}{ VOLAT } & Levin, Lin e Chu & $-11,763$ & 0.0000 & Estacionária \\
\hline & Im, Pesaran e Shin & $-7,476$ & 0.0000 & Estacionária \\
\hline & $\mathrm{ADF}$ & 249,192 & 0.0000 & Estacionária \\
\hline & PP & 216,505 & 0.0000 & Estacionária \\
\hline \multirow{4}{*}{ DESAL } & Levin, Lin e Chu & $-9,91$ & 0.0000 & Estacionária \\
\hline & Im, Pesaran e Shin & $-5,801$ & 0.0000 & Estacionária \\
\hline & $\mathrm{ADF}$ & 222,271 & 0.0000 & Estacionária \\
\hline & PP & 191,148 & 0.0000 & Estacionária \\
\hline \multirow{4}{*}{ DESAL_Amp } & Levin, Lin e Chu & $-17,365$ & 0.0000 & Estacionária \\
\hline & Im, Pesaran e Shin & $-13,249$ & 0.0000 & Estacionária \\
\hline & $\mathrm{ADF}$ & 380,225 & 0.0000 & Estacionária \\
\hline & $\mathrm{PP}$ & 392,746 & 0.0000 & Estacionária \\
\hline
\end{tabular}

Fonte: Elaboração própria a partir do software Eviews 10.

Nota: Para todos os métodos, a hipótese nula é de que as séries possuem raiz unitária (não estacionaria).

\section{Autor correspondente:}

Matheus Rissa Peroni Ribeiro

E-mail: matheus.peroni@unesp.br

Recebido em: 16/04/2019.

Aceito em: 09/03/2020.

\section{(cc) BY}

Este é um artigo de acesso aberto distribuído sob os termos da Creative Commons Attribution CC-BY 4.0, que permite uso irrestrito, distribuição e reprodução em qualquer meio, desde que o trabalho original seja devidamente citado. 